\title{
Nosing Around: Play in Pigs
}

\author{
Kristina Horback ${ }^{1 *}$ \\ ${ }^{1}$ School of Veterinary Medicine at University of Pennsylvania \\ *Corresponding author (Email: khorback@ vet.upenn.edu)
}

Citation - Horback, K. (2014). Nosing around: Play in pigs. Animal Behavior and Cognition, 1(2), 186-196. doi: 10.12966/abc.05.08.2014

\begin{abstract}
The predominant method of measuring welfare in swine focuses on overt physical ailments, such as skin lesions, lameness, and body condition. An alternative metric for assessing welfare in swine can be to measure the frequency and duration of positive behavioral states, such as play. Given that play occurs only when an animal's primary needs (food, comfort, safety, etc.) have been satisfied, it has been suggested that play may be a sensitive indicator for assessing the welfare of non-human animals. Play has primarily been described in young piglets and is assessed via the occurrence of specific play markers. These play markers include overt bursts of energy like scamper, or more subtle social behaviors like nose-to-body contact. This review describes four areas of play for swine: locomotor, object, sow-piglet, and, peer play. From sporadic leaping to combative wrestling, play behavior allows for the fine-tuning of reflexive behavior which can enhance physical development, enrich cognitive abilities, and facilitate the maintenance of social bonds.
\end{abstract}

Keywords - Play behavior, Domestic swine, Olfaction, Animal welfare

\section{Domestic swine natural history}

The current world population of domestic swine (Sus scrofa domesticus) is over 950 million (FAOSTAT, 2011). Not only are pigs the cornerstone of a multi-billion dollar industry, but they have played an important role in the religious, cultural and social domains of human history (Harris, 1989; McBride \& Key, 2003). The first domesticated pig originated from the Eurasian wild boar (Sus scrofa) in the Middle East between 9000 and 7000 B.C. (Giuffra et al., 2000; Porter, 1993). In 1539, Spanish explorer Hernando de Soto brought along the first swine to what is now the continental United States when he landed in Tampa Bay, Florida (Porter, 1993). After that historic day, invasive feral pigs have roamed the New World disturbing the natural ecosystem through soil disturbances and water contamination (Tisdell, 1982). Because pigs are opportunistic omnivores, feral herds can spend up onethird of the daylight rooting agricultural and wildlife-protected areas (Beattie, Walker, \& Sneddon, 1995; Stolba \& Wood-Gush, 1989).

\section{Swine behavior}

Groups of two to four sows with their litters, called sounders, are led by a dominant sow throughout a shared home range (D'Eath \& Turner, 2009). Through frequent nose-to-body and nose-tonose contact, swine use olfactory cues (i.e., pheromones) to recognize other individuals (Kristensen, Jones, Schofield, White, \& Wathes, 2001; Mendl, Randle, \& Pope, 2002; Stookey \& Gonyou, 1998;); which is fundamental in maintaining their social hierarchy. Animals with complex social structures, like 
swine, require special consideration to adequately stimulate their sensory systems. The maintenance of domestic pigs in group pens is often difficult due to the multifaceted requirements of pen size, compatible social grouping, and individual health care. One of the fundamental issues in animal welfare science is the application of enrichment to increase natural behaviors (Newberry, 1995). In addition to safe shelter, adequate nutrition and veterinary care, the ability to express specific behaviors in a species is an essential measurement of animal welfare (i.e., five freedoms: Webster, 2000). Enrichment is most often implemented within zoological, laboratory, and agricultural settings to increase natural behaviors while reducing stereotypic behavior. Stereotypic behavior can be defined as "repetitive, invariant behavior patterns with no obvious goal or function" (Mason, 1991, p. 1015). Common stereotypic behavioral patterns in domestic swine are often based on oral-nasal activity, such as bar-biting, sham-chewing, drinker-pressing, head-weaving, nose-rubbing, and tongue-rolling (Broom, 1986; Robert, Rushen, \& Farmer, 1997; Stolba, Baker, \& Wood-Gush, 1983; Vieuille-Thomas, Le Pape, \& Signoret, 1995). The addition of substrates such as straw, peat and mushroom compost to swine housing has been shown to decrease common stereotypic behaviors and aggression toward pen mates (Arey, 1993; Beattie et al., 1995; Fraser, Phillips, Thompson, \& Tennessen, 1991; Kelly, Bruce, English, Fowler, \& Edwards, 2000; Sneddon, Beattie, Walker, \& Weatherup, 2001; Wood-Gush \& Beilharz, 1983). Furthermore, the provision of enrichment objects, like plastic dog toys or hanging rope, can increase both social and solitary play, which can be an indicator of physical and psychological well-being (Barnes, Levitsky, Pond, \& Moore, 1976; Blackshaw, Thomas, \& Lee, 1997; Śpinka, Newberry, \& Bekoff, 2001; Worsaae \& Schmidt, 1980).

\section{Play behavior}

While there is a growing field of research on swine intelligence (i.e., problem-solving: Broom, Sena, \& Moynihan, 2009; cognitive bias: Douglas, Bateson, Walsh, Bedue, \& Edwards, 2012; spatial memory and deception: Mendl, Held, \& Byrne, 2010), the assessment of play behavior in domestic pigs is somewhat lacking. This may be due to the difficulty in identifying play signals, such as distinguishing reciprocal contact like head-butting and mounting between genuine conflict and rough-and-tumble play. According to Burghardt (2005), there are five basic criteria for a behavior to be considered play: (1) the behavior is not fully functional, (2) the behavior is spontaneous, voluntary, pleasurable, or autotelic ("done for its own sake"), (3) the behavior differs from "serious" behavior in terms of its form, duration, and/or frequency, (4) the behavior is repeatedly performed, but not stereotyped, and (5) the behavior occurs when the animal is healthy and free from stress. In general, swine ethologists have maintained these five elements in their definition of play in their research of young piglets, with ages ranging from birth to four weeks old. Swine play behavior is assessed via the occurrence of specific play markers (Table 1), such as overt bursts of energy like scamper, or more subtle social behaviors like nose-to-body contact (Dobao, Rodribanez, \& Siliŏ, 1985; Donaldson, Newberry, Špinka, \& Cloutier, 2002; McBride, 1963; Newberry, Wood-Gush, \& Hall, 1988). 
Table 1

Description of Solitary and Social Play Markers in Swine

\begin{tabular}{ll}
\hline Play Marker & \multicolumn{1}{c}{ Description } \\
\hline Solitary Play & Jump up and down on the spot while facing in one direction. \\
Hop/Spring & A sequence of at least two forward hops in rapid succession, usually accompanied by ear flapping. \\
Scamper & Sudden forward motion either towards or away from conspecific. \\
Sprint & Jump or whirl around to face in a different direction. \\
Pivot & Exaggerated lateral displacements of the head and neck in the horizontal plane, involving at least \\
Toss head & one full movement to each side. \\
& $\begin{array}{l}\text { Move forward carrying object or material which protrudes from mouth. } \\
\text { Carry object }\end{array}$ \\
Shake object & Perform vigorous lateral movements of head and neck while holding object or material which \\
& protrudes from mouth (e.g., straw). Includes shaking and tugging at loose end of fixed object (e.g. \\
& rope).
\end{tabular}

Social Play

Mother-infant

Rough-and-tumble
Naso-naso investigation, call-back vocalizations, reciprocal mouthing and tactile contact between a sow and her piglets.

Two or more piglets engaged in wrestling, chasing, reciprocal biting and belly-nudging (e.g., levering). Often initiated by pivoting and head tossing.

\section{Solitary play}

Locomotor play. The most common type of play found more often in piglets than adults is locomotor play. This behavior corresponds to the isolated, sporadic movement such as scampering or leaping, and is distinctive from overt "avoidance of a predator or conspecifics ... by the player's loose body tone... and by the repetition and ease of interruption of its activity" (Fagen, 1981, p. 8). In general, locomotor play is displayed by species that live in unstable environments rather than static environments (Špinka et al., 2001). The home ranges of wild and feral swine are greatly influenced by food availability, weather, and hunting pressure (Graves, 1984). Therefore, the ability to react quickly to changing environmental stimuli through hasty behavior changes is beneficial for survival. Once piglets are physiologically mature, around 3 to 5 days, they are able to run, jump and maneuver around the body of the sow (Blackshaw, Swain, Blackshaw, Thomas, \& Gillies, 1997; Dobao et al., 1985; Newberry et al., 1988). The occurrence of a jump, spring, hop, sprint, scamper, trot, or head tossing are play markers which define locomotor play in swine (Blackshaw, Swain, et al., 1997; D’Eath \& Turner, 2009; Dobao et al., 1985; Jensen, 1980; Newberry et al., 1988 ). This type of loose body activity has been reported to be most frequent in pigs between the ages of 2 and 6 weeks (Blackshaw, Swain, et al., 1997; Newberry et al., 1988). Rauw (2013) reported an immediate increase in locomotor play duration and rate after releasing 6 week old piglets into a corridor near their home pens. The novelty of the hallway, and the increase in square foot per pig, allowed for sudden bursts in individual scampering and running. This spurt of energy upon entering a new environment is also seen in sows that are weaned after several weeks of low activity while housed with their piglets. These weaned sows often run or trot from their farrowing rooms without provocation, display sporadic head tosses, and appear to be bouncing (I. Rodriguez, personal communication, November $\left.20^{\text {th }}, 2013\right)$.

Locomotor play is suggested to be beneficial for piglets because it facilitates the development and coordination of skeletal muscles, and encourages behavioral flexibility (Byers, 1998; Špinka et al., 2001). At nursing time, piglets must be aware of where the sow is preparing to lie down in order to quickly avoid a crushing death (Damm, Forkman, \& Pedersen, 2005). Therefore, the physical and mental skills acquired through locomotor play may enhance a piglet's survival. A restricted early environment due to a limited size or lack of bedding may prevent locomotor play in piglets. This lack of exercise could produce abnormal physical development such as splay leg, joint swelling, hock lesions, and lameness (Barnett, Hemsworth, Cronin, Jongman, \& Hutson, 2000; Bonde, Rousing, Badsberg, \& Sørensen, 2004; Zoric, Nilsson, Mattsson, Lundeheim, \& Wallgren, 2008). Stocking density may be the most important factor for 
the development of healthy limbs in swine. By providing adequate pen space, pork producers can increase the occurrence of locomotor play, which may indirectly prevent future health issues.

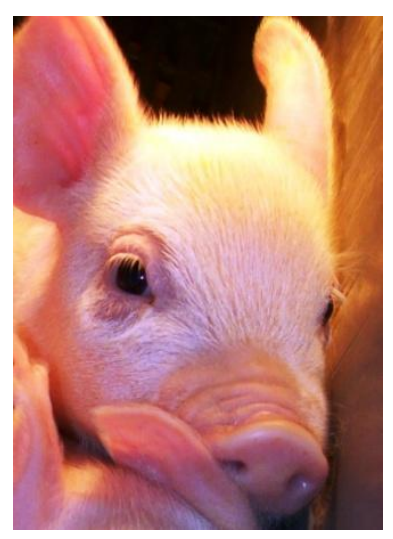

Figure 1. Piglets engage in play behavior starting around 3 to 5 days old.

Object play. Object play involves the physical manipulation of inanimate items such as twigs, rocks or other moveable pieces in an animal's environment (Burghardt, 2005; Hall, 1998). In pigs, this manipulation occurs using the snout or front limbs, such as biting, sniffing, pushing, kicking, licking, and chewing (Blackshaw, Swain et al., 1997; Johnson, Morrow-Tesch, \& McGlone, 2001). For economic purposes, enrichment items used in farms are often indestructible like bowling balls and metal chains. Although these objects may last long, the pigs are thought to be neophilic and tend to lose interest quickly (Studnitz, Jensen, \& Pedersen, 2007; Wood-Gush \& Vestergaard, 1991). The best enrichment items to keep interest in pigs should change continually upon manipulation, and, of course, are safe to consume. These items include bedding substrate (compost, straw, coconut fiber, or mushroom peat), and edible objects (stacks of paper, cotton rope, and cloth strips). Elements of barn structure, such as gating, nipple drinkers, rubber mats, and slatted floors can become unintentional enrichment items if no other objects are provided. Pigs may develop self-inflicted wounds while trying to manipulate these objects (i.e., repeated chewing of metal bars causing wounds to mouth and snout), or can harm others by diverting such behavior toward conspecifics such as belly nosing, ear biting, and tail biting (Broom, 1986; Fraser et al., 1991; Stolba et al., 1983).

A)

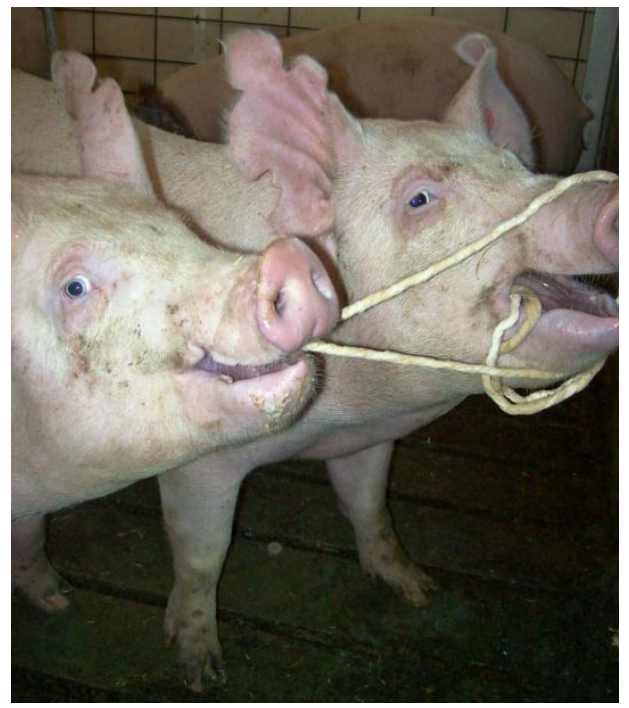

B)

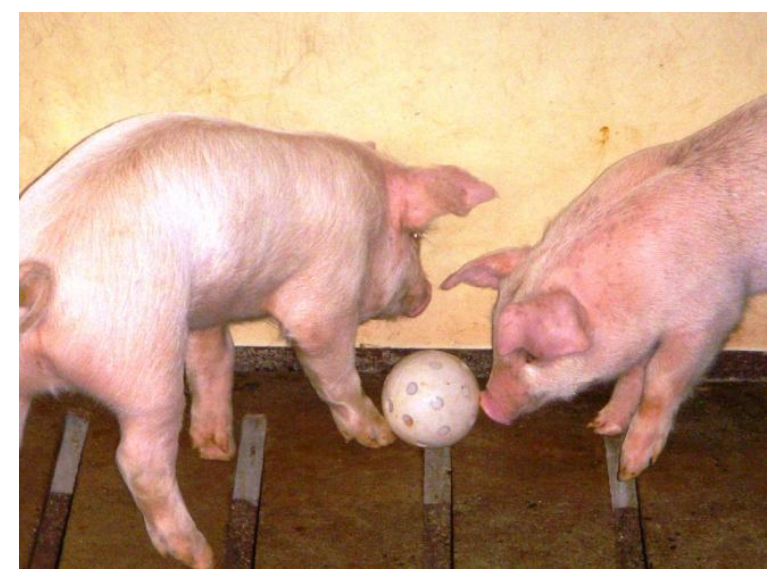

Figure $2 A, B$. Object play in pigs. 
The tenacious curiosity of omnivorous pigs is fueled by the instinct to dig up and gnaw on objects to test for edibility (Studnitz et al., 2007). Pigs explore their environments in order to evaluate both the extrinsic value of their surroundings (i.e., shelter, food, water source) and the intrinsic value (i.e., social group, pen size) (Studnitz et al., 2007; Wood-Gush \& Vestergaard, 1989). Just as cats need to scratch and dogs need to chew, pigs need to root. The wide cartilage disk located at the tip of the snout functions as a plow to till soil and locate grubs (Studnitz et al., 2007). When pigs are prevented from rooting by being housed indoors permanently (Day, Kyriazakis, \& Lawrence, 1995) or by wearing a nose ring (Studnitz, Jensen, \& Jørgensen, 2003), they will immediately root the earth as soon as they are given access (Studnitz \& Jensen, 2002). Given that oral/nasal investigation of the environment appears to be a high priority behavior for pigs, the provision of malleable toys is highly recommended in commercial barns. Research has shown that pen size has no significant effect on toy choice, object play rate or duration in 4 week old piglets (Apple \& Craig, 1992). Furthermore, group pens with either static or mobile enrichment toys will exhibit significantly lower levels of social aggression than weaned pigs housed without toys (Blackshaw, Thomas et al., 1997). With minimal economic and temporal costs, farms can increase healthy activity, reduce fighting, and encourage species-specific behavior in young and mature pigs by simply providing suitable toys.

\section{Social play}

Sow-piglet play. Neonatal piglets are highly dependent upon the sow for vital colostral milk gamma globulins (Curtis \& Bourne, 1971), ambient body heat for temperature regulation, and protection from predators (Hartsock \& Graves, 1976; Nowak, Porter, Lévy, Orgeur, \& Schaal, 2000). The sow also serves as an important source of various environmental stimuli for the piglets. Using tactile, vocal, and olfactory communication, piglets navigate their way around the sow's body with the main goal of locating the teats for nursing (Horrell \& Hodgson, 1992; McBride, 1963). Within the first two days after birth, piglets will spend a large portion of the day climbing on, nudging, or biting the sow's teats, snout, ears, hooves, tail, and vulva (Dobao et al., 1985; Blackshaw, Swain et al., 1997). In return, sows will nudge and mouth the piglets, while grunting softly, as they crawl past her head during exploration (Whatson \& Bertram, 1982). This form of mother-offspring play, along with naso-naso contact and call-back vocalizations, are important behaviors in establishing the maternal bond since the sow does not groom her young (Blackshaw, Swain et al., 1997; Walser, 1986; Whatson \& Bertram, 1982).

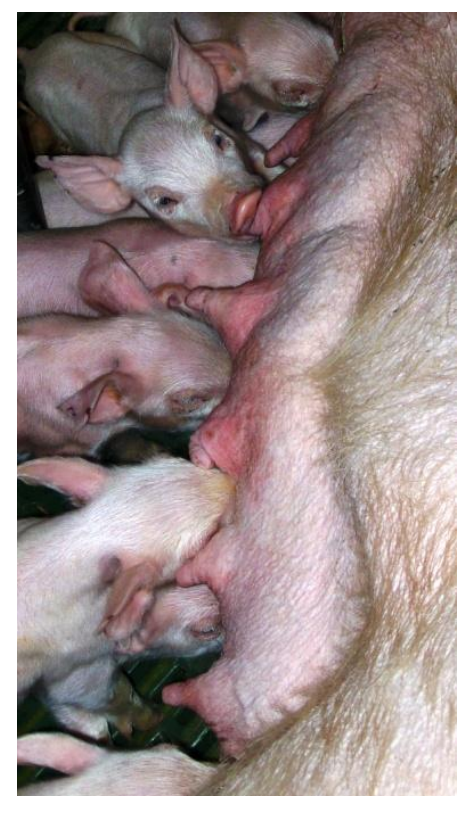


Figure 3. Guided by scent, the teat order of a litter is established immediately after birth.

Piglets are able to discriminate odors from their nest (e.g., sow's urine, udders) as early as one day old and can identify their mother's vocalizations soon after (Horrell \& Hodgson, 1992; Walser, 1986). During the first 2 post-partition days, feral sows spend an average $76 \%$ of her time lying in their nests. Sow resting behavior decreases to approximately $42 \%$ after 3 weeks, and sows tend to forage at greater distances $(>10 \mathrm{~m}$ ) from the nest (Csermely, 1994). Sow-piglet play progressively reduces 4 weeks after farrowing throughout weaning, as the sow increases foraging behavior while decreasing resting and nursing (Csermely, 1994; Johnson et al., 2001). Mutual play among mothers and offspring is thought to strengthen the attachment and establish the foundation for future peer play (Burghardt, 2005). This transient play behavior allows piglets to practice using odorants for social recognition (Ewbank, Meese, \& Cox,1974; Mendl et al., 2002), nosing their environment for resources (Studnitz et al., 2007), and developing the motor skills necessary for rough-and-tumble play with their peers (Bekoff, 1984).

Peer play. Piglets will engage in antagonistic tussling within minutes of being born while teat order is disputed (Algers, 1993; Fraser \& Jones, 1975; McBride, 1963). This early social interaction often determines future dominance and aggression levels among the litter, with piglets positioned at the anterior teats being more dominant and those in the middle teats fighting more frequently (Ruis et al., 2000; Sundman, 2011). As nursing occurs roughly once per hour for 20 to 30 seconds, piglets have ample time to engage in mock combat to practice fighting skills. This type of peer play, called rough-and-tumble play, begins around 3 to 5 days old and is rarely seen in pigs after reaching sexual maturity ( 6 months) (Dobao et al., 1985; Newberry et al., 1988). Rough-and-tumble play occurs between two or more littermates and often involves a head-on stance, pushing and nudging of peer's shoulder or belly, biting of shoulder and ears, and chasing (Dobao et al., 1985; Donaldson et al., 2002; Johnson et al., 2001; Newberry et al., 1988). These encounters can last anywhere from a few seconds to several minutes, and mimic the fighting posture of adult swine, called parallel-pressing (Jensen, 1980). The key element of rough-and-tumble play is the occurrence of a play signal, which cues the social partner that behaviors produced are not as serious as they normally would be in other contexts (Bateson, 1955; Bekoff, 1975). Based on sequential analysis of social play markers in piglets, pivoting and head tossing is suggested to function as play signals to initiate rough-and-tumble play for this species (Newberry et al., 1988).

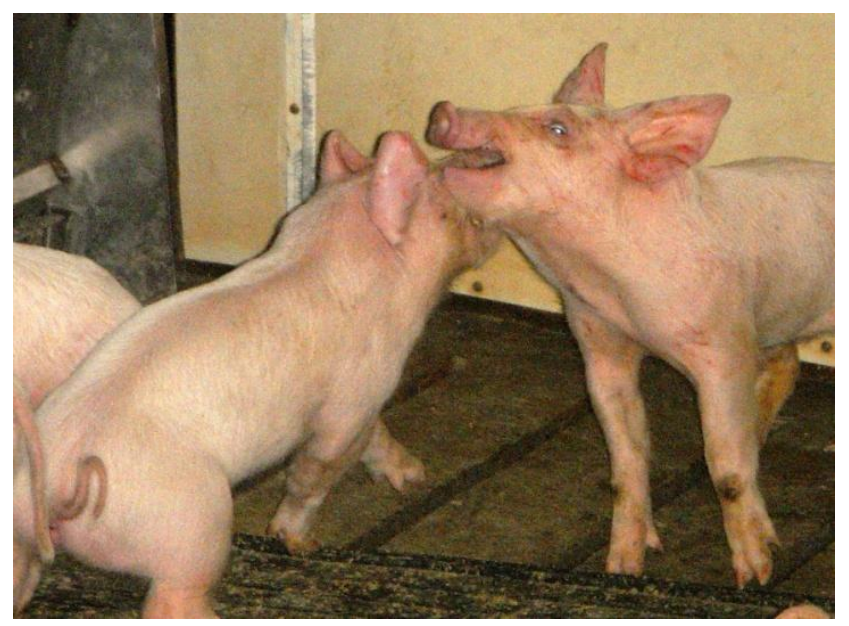

Figure 4. Rough-and-tumble play in weaned piglets.

Weaning piglets from their sow is one of the most significant practices in modern pig production. In most commercial farms, piglets are weaned anywhere between 20 and 35 days old, while free-ranging sows wean their piglets around 60 to 137 days old (Jensen \& Recen, 1989; Newberry \& Wood-Gush, 1985). This process can be highly stressful due to unfamiliar transport, shifting of diet to solids, pathogens of a new environment, and an increase in aggression as the dominance hierarchy of unfamiliar 
piglets is established (Held \& Mendl, 2001; Jensen \& Recen, 1989). Social play, including mock combat and reciprocal tactile contact, allows piglets to develop the social skills necessary to integrate into a hierarchical social system (Bekoff 1984; Fagen, 1981). This includes motor skills needed for successful fighting, and olfactory communication skills needed when sizing up peers (Bekoff \& Byers, 1981; Dobao et al., 1985; Kristensen et al., 2001). There are inconsistent reports in the swine behavior literature indicating that rough-and-tumble play is exhibited more in males (Dobao et al., 1985), in females (Rauw, 2013), and that no sex differences in social play behavior exists (Newberry et al., 1988). A common report, however, is that weaned piglets tend to preferentially play with same sex partners or littermates (Dobao et al., 1985).

\section{Welfare implications}

From sporadic leaping to combative wrestling, play behavior enhances an animal's rapid response to novel situations, which provides adaptive and competitive advantages (Bekoff, 1984; Špinka et al., 2001). This fine-tuning of reflexive behavior enriches cognitive development in young animals (Bekoff \& Byers, 1998; Fagen, 1981) and facilitates the maintenance of social bonds (Bekoff, 1984; Byers, 1984, Kuczaj, Makecha, Trone, Paulos, \& Ramos, 2006). Play is classified as a positive-affect behavior because it is correlated to high levels of acetylcholine, glutamate, and opioids (i.e., "pleasure" neurotransmitters), and, activity of subcortical brain areas that mediate the hedonic properties of reward (Berridge \& Kringelbach, 2008; Burgdorf \& Panksepp, 2007; Kuczaj \& Horback, 2012). In addition, a negative correlation between plasma cortisol levels and play behavior rates have been reported in numerous species, supporting the notion that play rarely occurs when an animal is stressed (Biben \& Champoux, 1999; Worsaae \& Schmidt, 1980). Given that play occurs only when an animal's primary needs (food, comfort, safety, etc.) have been satisfied, it has been suggested that play may be a sensitive indicator for assessing the welfare of animals (Burghardt 2005; Fagen, 1981; Oliveira, Rossi, Silva, Lau, \& Barreto, 2010). A decline in the frequency of play behavior in piglets can be a sign of issues with physical or psychological well-being.

Play behavior in swine has been shown to be affected by adverse physical and environmental conditions (Beattie et al., 1995; Newberry et al., 1988). For example, Barnes et al. (1976) reported that malnourished piglets spent less time engaged in object play than well-nourished piglets. The lack of play in commercial pigs may appraise the welfare properties of certain swine housing systems. Piglets reared under restrictive housing conditions may be unable to express their full repertoire of playful behavior due to limitations of space, social companions, or interactive objects. Research has shown that pigs raised in barren conditions can develop deviant aggressive play behavior, which can develop into poor social skills as adults (Beattie et al., 1995; Schouten, 1991). Furthermore, it has been shown that barren rearing environments may affect pre-slaughter stress and subsequent meat quality (Geverink et al., 1998), while the provision of environmental and social enrichment may increase growth rates (Morgan, Deans, Lawrence, \& Nielsen, 1998) and back fat levels (Barton-Gade, 1987). Therefore, swine producers can benefit financially by improving the welfare of pigs via the implementation of adequate social grouping and environmental stimuli. 


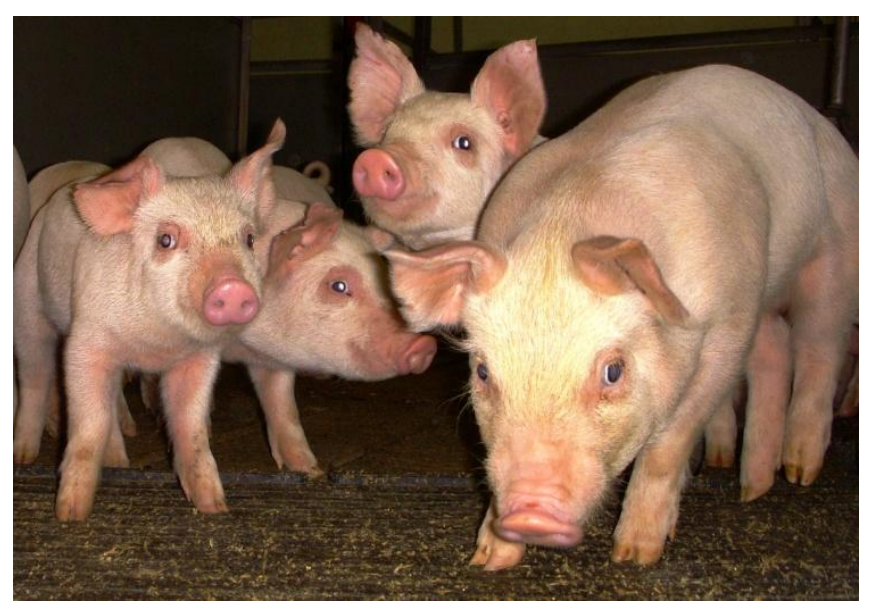

Figure 5. Group housing of weaned piglets allows for the practice of important social skills.

\section{Conclusion}

The predominant method of measuring welfare in swine focuses on overt physical ailments, such as skin lesions, lameness, and body condition. An alternative metric for assessing welfare in swine is to measure the frequency and duration of positive behavioral states, such as play. Because pigs have an omnivorous diet, live in complex social systems, and utilize multi-modal communication, they require multifaceted sensory stimulation to maintain a healthy well-being. The application of species-specific enrichment (e.g., rope, straw, compost) can increase natural behaviors of chewing and rooting while simultaneously reducing aggressive social behavior and harmful stereotypic behavior. In fact, research has shown that merely conditioning pigs to the anticipation of enrichment (i.e., doorbell ring) can be used to facilitate play behavior in piglets (Dudink, Simonse, Marks, de Jonge, \& Spruijt, 2006; de Jonge, Boleij, Baars, Dudink, \& Spruijt, 2008). Encouraging pigs to scamper, interact with their environment, and socialize with peers does not require great effort - but often results in great rewards.

\section{References}

Algers, B. (1993). Nursing in pigs: Communicating needs and distributing resources. Journal of Animal Science, 71, 2826-2831.

Apple, J. K, \& Craig, J. V. (1992). The influence of pen size on toy preference of growing pigs. Applied Animal Behavior Science, 35, 149-155.

Arey, D. S. (1993). The effect of bedding on the behaviour and welfare of pigs. Animal Welfare, 2, 235-246.

Barnes, R. H., Levitsky, D. A., Pond, W. G. \& Moore, U. (1976). Effect of postnatal dietary protein and energy restriction on exploratory behavior in young pigs. Developmental Psychobiology, 9, 425-435.

Barnett, J. L., Hemsworth, P. H., Cronin, G. M., Jongman, E. C., \& Hutson, G. D. (2000). A review of the welfare issues for sows and piglets in relation to housing. Crop and Pasture Science, 52, 1-28.

Barton-Gade, P. A. (1987). Meat and fat quality in boars, castrates and gilts. Livestock Production Science, 16, $187-$ 196.

Bateson, G. (1955). A theory of play and fantasy. Psychiatric Research Reports, 2, 39-51.

Beattie, V. E., Walker, N., \& Sneddon, I. A. (1995). Effects of environmental enrichment on behaviour and productivity of growing pigs. Animal Welfare, 4, 207-220.

Bekoff, M. (1975). The communication of play intention: Are play signals functional? Semiotica, 15, 231-239.

Bekoff, M. (1984). Social play behavior. Bioscience, 34, 228-233.

Bekoff, M., \& Byers, J. A. (1981). A critical reanalysis of the ontogeny of mammalian social and locomotor play: An ethological hornet's nest. In K. Immelman, G. W. Barlow, \& L. Petrinovich (Eds.), Behavioral development: The Bielefeld interdisciplinary project (pp. 296-337). New York, NY: Cambridge University Press. 
Berridge, K. C. \& Kringelbach, M. L. (2008). Affective neuroscience of pleasure: Reward in humans and animals. Psychopharmacology, 199, 457-480.

Biben, M. \& Champoux, M. (1999). Play and stress: Cortisol as a negative correlate of play in Saimiri. Play \& Culture Studies, 2, 191-208.

Blackshaw, J. K., Swain, A. J., Blackshaw, A. W., Thomas, F. J. M., \& Gillies, K. J. (1997). The development of playful behaviour in piglets from birth to weaning in three farrowing environments. Applied Animal Behaviour Science, 55, 37-49.

Blackshaw, J. K., Thomas, F. J., \& Lee, J. A. (1997). The effect of a fixed or free toy on the growth rate and aggressive behaviour of weaned pigs and the influence of hierarchy on initial investigation of the toys. Applied Animal Behaviour Science, 53, 203-212.

Bonde, M., Rousing, T., Badsberg, J. H., \& Sørensen, J. T. (2004). Associations between lying down behaviour problems and body condition, limb disorders and skin lesions of lactating sows housed in farrowing crates in commercial sow herds. Livestock Production Science, 87, 179-187.

Broom, D. M. (1986). Stereotypies and responsiveness as welfare indicators in stall-housed sows. Animal Production, 42, 438-439.

Broom, D. M., Sena, H., \& Moynihan, K. L. (2009). Pigs learn what a mirror image represents and use it to obtain information. Animal Behavior, 78, 1037-1041.

Burgdorf, J., \& Panksepp, J. (2007). The neurobiology of positive emotions. Neuroscience and Biobehavioural Reviews, 30, 173-187.

Burghardt, G. M. (2005). The genesis of animal play. Cambridge, MA: MIT Press.

Byers, J. A. (1984). Play in ungulates. In P. K. Smith (Ed.), Play in animals and humans (pp.43 - 65). Oxford, UK: Basil Blackwell.

Byers, J. A. (Ed.). (1998). Animal play: Evolutionary, comparative and ecological perspectives. Cambridge, UK: Cambridge University Press.

Csermely, D. (1994). Maternal behaviour of free ranging sows during the first 8 days after farrowing. Journal of Ethology, 12, 53-62.

Curtis, J., \& Bourne, F. J. (1971). Immunoglobulin quantitation in sow serum, colostrum and milk and the serum of young pigs. Biochimica et Biophysica Acta (BBA)-Protein Structure, 236, 319-332.

Damm, B. I., Forkman, B., \& Pedersen, L. J. (2005). Lying down and rolling behaviour in sows in relation to piglet crushing. Applied Animal Behaviour Science, 90, 3-20.

Day, J. E. L., Kyriazakis, I., \& Lawrence, A. B. (1995). The effect of food deprivation on the expression of foraging and exploratory behaviour in the growing pig. Applied Animal Behaviour Science, 42, 193-206.

D'Eath, R. B., \& Turner, S. P. (2009). The natural behaviour of the pig. In W. Sybesma (Ed.), The welfare of pigs (pp.13-45). The Netherlands: Springer.

Dobao, M. T., Rodribanez, J., \& Siliŏ, L., 1985. Choice of companions in social play in piglets. Applied Animal Behaviour Science, 13, 259-266.

Donaldson, T. M., Newberry, R. C., Špinka, M., \& Cloutier, S. (2002). Effects of early play experience on play behaviour of piglets after weaning. Applied Animal Behavior Science, 70, 221-231

Douglas, C., Bateson, M., Walsh, C., Bedue, A., \& Edwards, S. (2012). Environmental enrichment induces optimistic cognitive biases in pigs. Applied Animal Behavior Science, 139, 65-73.

Dudink, S., Simonse, H., Marks, I., de Jonge, F. H., \& Spruijt, B. M. (2006). Announcing the arrival of enrichment increases play behaviour and reduces weaning-stress-induced behaviours of piglets directly after weaning. Applied Animal Behaviour Science, 101, 86-101.

Ewbank, R., Meese, G. B., \& Cox, J. E. (1974). Individual recognition and the dominance hierarchy in the domesticated pig. The role of sight. Animal Behaviour, 22, 473-480.

Fagen, R. M. (1981). Animal play behavior. New York, NY: Oxford University Press.

Food and Agriculture Organization of the United Nations (FAOSTAT, 2011). Available at http://faostat.fao.org/site/362/DesktopDefault.aspx?PageID=362

Fraser, D. \& Jones, R. (1975). The 'teat order' of suckling pigs: I. Relation to birth weight and subsequent growth. The Journal of Agricultural Science, 84, 387-391.

Fraser, D., Phillips, P. A., Thompson, B. K., \& Tennessen, T. (1991). Effect of straw on the behaviour of growing pigs. Applied Animal Behaviour Science, 30, 307-318.

Geverink, N. A., Kappers, A., Van de Burgwal, E., Labooij, E., Blokhuis, J., \& Wiegant, V. (1998). Effects of regular moving and handling on the behavioral and physiological responses of pigs to pre-slaughter treatment and consequences for meat quality. Journal of Animal Science, 76, 2080-2085. 
Giuffra, E., Kijas, J. M. H., Amarger, V., Carlborg, Ö., Jeon, J. T., \& Andersson, L. (2000). The origin of the domestic pig: Independent domestication and subsequent introgression. Genetics, 154, 1785-1791.

Graves, H. B. (1984). Behavior and ecology of wild and feral swine (Sus scrofa). Journal of Animal Science, 58, 482-492.

Hall, S. L. (1998). Object play by adult animals. In M. Bekoff \& J. A. Byers (Eds.), Animal play (pp. 27-44). Cambridge, UK: Cambridge University Press.

Harris, M. (1989). Cows, pigs, wars, and witches: The riddles of culture. New York, NY: Random House.

Hartsock, T. G., \& Graves, H. B. (1976). Neonatal behavior and nutrition-related mortality in domestic swine. Journal of Animal Science, 42, 235-241.

Held, S., \& Mendl, M. (2001). Behaviour of the young weaner pig. In M. Varley \& J. Wisemen (Eds.), The weaner pig, nutrition and management (pp. 273-297). Wallingford, UK: CABI Publishing.

Horrell, I., \& Hodgson, J. (1992). The bases of sow-piglet identification. 2. Cues used by piglets to identify their dam and home pen. Applied Animal Behaviour Science, 33, 329-343.

Jensen, P. (1980). An ethogram of social interaction patterns in group housed dry sows. Applied Animal Ethology, 6, 341-350.

Jensen, P., \& Recen, B. (1989). When to wean: Observations from free-ranging domestic pigs. Applied Animal Behaviour Science, 23, 49-60.

Johnson, A. K., Morrow-Tesch, J. L., \& McGlone, J. J. (2001). Behavior and performance of lactating sows and piglets reared indoors or outdoors. Journal of Animal Science, 79, 2571-2579.

de Jonge, F. H., Boleij, H., Baars, A. M., Dudink, S., \& Spruijt, B. M. (2008). Music during play-time: Using context conditioning as a tool to improve welfare in piglets. Applied Animal Behaviour Science, 115, 138148.

Kelly, H. R. C., Bruce, J. M., English, P. R., Fowler, V. R., \& Edwards, S. A. (2000). Behaviour of 3-week weaned pigs in Straw-Flow, deep straw and flatdeck housing systems. Applied Animal Behaviour Science, 68, 269280 .

Kristensen, H. H., Jones, R. B., Schofield, C. P., White, R. P., \& Wathes, C. M. (2001). The use of olfactory and other cues for social recognition by juvenile pigs. Applied Animal Behaviour Science, 72, 321-333.

Kuczaj, S. A., \& Horback, K. M. (2012). Play and emotions. In S. Watanabe and S. Kuczaj (Eds.), Comparative perspectives on human and animal emotions (pp. 87-112). Tokyo, Japan: Springer.

Kuczaj, S. A., Makecha, R., Trone, M., Paulos, R. D., \& Ramos, J. A. (2006). Role of peers in cultural innovation and cultural transmission: Evidence from the play of dolphin calves. International Journal of Comparative Psychology, 19, 223-240.

Mason, G. (1991). Stereotypies: A critical review. Animal Behaviour, 41, 1015-37.

McBride, G. (1963). The "teat order" and communication in young pigs. Animal Behaviour, 11, 53-56.

McBride, W., \& Key, N. (2003). Economic and structural relationships in US hog production. USDA-Economic Research Service Agricultural Economic Report 818.

Mendl, M., Randle, K., \& Pope, S. (2002). Young female pigs can discriminate individual differences in odours from conspecific urine. Animal Behavior, 64, 97-101.

Mendl, M., Held, S., \& Byrne, R. W. (2010). Pig cognition. Current Biology, 20, R796-R798.

Morgan, C. A., Deans, L. A., Lawrence, A. B., \& Nielsen, B. L. (1998). The effects of straw bedding on the feeding and social behaviour of growing pigs fed by means of single- space feeders. Applied Animal Behaviour Science, 58, 23-33.

Newberry, R. C. (1995). Environmental enrichment: increasing the biological relevance of captive environments. Applied Animal Behaviour Science, 44(2), 229-243.

Newberry, R. C., \& Wood-Gush, D. G. M. (1985). The suckling behavior of domestic pigs in a semi-natural environment. Behaviour, 95, 11-25.

Newberry, R. C., Wood-Gush, D. G. M., \& Hall, J. W. (1988). Playful behaviour of piglets. Behavioural Processes, 17(3), 205-216.

Nowak, R., Porter, R. H., Lévy, F., Orgeur, P., \& Schaal, B. (2000). Role of mother-young interactions in the survival of offspring in domestic mammals. Reviews of Reproduction, 5, 153-163.

Oliveira, A., Rossi, A., Silva, L., Lau, M. \& Barreto, R. E. (2010). Play behaviour in nonhuman animals and the animal welfare issue. Journal of Ethology, 28, 1-5.

Porter, V. (1993). Pigs. A handbook to the breeds of the world. Mountfield, UK: Helm Information.

Rauw, W. M. (2013). A note on the consistency of a behavioral play marker in piglets. Journal of Animal Science and Biotechnology, 4, 33. 
Robert, S., Rushen, J., \& Farmer, C. (1997). Both energy and bulk food affect stereotypic behaviour, heart rate, and feeding motivation of female pigs. Applied Animal Behaviour Science, 54, 161-171.

Ruis, M. A., Brake, J. H., van de Burgwal, J. A., de Jong, I. C., Blokhuis, H. J., \& Koolhaas, J. M. (2000). Personalities in female domesticated pigs: Behavioural and physiological indications. Applied Animal Behavior Science, 66, 31-47.

Schouten, W. G. P. (1991). Effects of rearing on subsequent performance in pigs. Pig News and Information, 12, 245-247.

Sneddon, I. A., Beattie, V. E., Walker, N., \& Weatherup, R. N. (2001). Environmental enrichment of intensive pig housing using spent mushroom compost. Animal Science, 72, 35-42.

Špinka, M., Newberry, R. C., Bekoff, M. (2001). Mammalian play: Training for the unexpected. The Quarterly Review of Biology, 76, 141-168.

Stolba, A., Baker, N., \& Wood-Gush, D. G. M. (1983). The characterisation of stereotyped behaviour in stalled sows by informational redundancy. Behaviour, $87,157-182$.

Stolba, A., \& Wood-Gush, D. G. M. (1989). The behaviour of pigs in a semi-natural environment. Animal Production, 48, 419-425.

Stookey, J. M., \& Gonyou, H.W. (1998). Recognition in swine: Recognition through familiarity or genetic relatedness? Applied Animal Behaviour Science, 55, 291-305

Studnitz, M., \& Jensen, K. H. (2002). Expression of rooting motivation in gilts following different lengths of deprivation. Applied Animal Behaviour Science, 76, 203-213.

Studnitz, M., Jensen, K. H., \& Jørgensen, E. (2003). The effect of nose rings on the exploratory behaviour of outdoor gilts exposed to different tests. Applied Animal Behaviour Science, 84, 41-57.

Studnitz, M., Jensen, M. B., \& Pedersen, L. J. (2007). Why do pigs root and in what will they root?: A review on the exploratory behaviour of pigs in relation to environmental enrichment. Applied Animal Behaviour Science, 107, 183-197.

Sundman, A. S. (2011). Personality in piglets: Is there a difference in personality traits between pigs from different teat order positions? (Unpublished doctoral dissertation). Linköping University, Linköping, Sweden.

Tisdell, C. A. (1982). Wild pigs: Environmental pest or economic resource. Oxford, UK: Pergamon Press.

Vieuille-Thomas, C., Le Pape, G., \& Signoret, J. P. (1995). Stereotypies in pregnant sows: Indications of influence of the housing system on the pattern expressed by animals. Applied Animal Behaviour Science, 44, 19-27.

Walser, E. (1986). Recognition of the sow's voice by neonatal piglets. Behaviour, 99, 177-188.

Webster, A. J. F. (2000). Farm animal welfare: The five freedoms and the free market. Veterinary Journal, 161, 229 237.

Whatson, T. S., \& Bertram, J. M. (1982). Some observations of mother infant interactions in the pig (Sus scrofa). Applied Animal Ethology, 9, 253-261.

Wood-Gush, D. G. M., \& Beilharz, R. G. (1983). The enrichment of a bare environment for animals in confined conditions. Applied Animal Science, 50, 336-341.

Wood-Gush, D. G. M., \& Vestergaard, K. S. (1989). Exploratory behavior and the welfare of intensively kept animals. Journal of Agricultural Ethics, 2, 161-169.

Wood-Gush, D. G. M., \& Vestergaard, K. (1991). The seeking of novelty and its relation to play. Animal Behaviour, 42, 599-606.

Worsaae, H., \& Schmidt, M. (1980). Plasma cortisol and behaviour in early weaned piglets. Acta Veterinaria Scandinavica, 21, 640-657.

Zoric, M., Nilsson, E., Mattsson, S., Lundeheim, N., \& Wallgren, P. (2008). Abrasions and lameness in piglets born in different farrowing systems with different types of floor. Acta Veterinaria Scandinavica, 50, 37. 